\section{Coalizão partidária, aporte financeiro e desempenho da assistência médica e odontológica em duas regiões de saúde brasileiras}

\author{
Party coalitions, budget outlay, and performance \\ of medical and dental care in two health \\ regions of Brazil
}

\section{Coalición partidaria, aporte financiero y desempeño de la asistencia médica y odontológica en dos regiones de salud brasileñas}

Joana Danielle Brandão Carneiro 1 Aylene Emilia Moraes Bousquat 1

Paulo Frazão 1

\title{
Resumo
}

Coalizações de governo distintas encontram limites para produzir mudanças na orientação de políticas. O objetivo foi descrever a orientação política dos partidos de coalização, o aporte financeiro, a estrutura e o desempenho da assistência médica e odontológica em duas regiões de saúde brasileiras distintas socioeconomicamente e na oferta de serviços. Utilizaram-se indicadores a partir de dados oficiais relativos ao período de 2007 a 2014 e caraterísticas da coalização partidária definidas pelas preferências eleitorais municipais e de intensidade da competição eleitoral em cada estado da respectiva região. Maior aporte financeiro per capita e maior porcentagem de população potencialmente coberta pela atenção básica e pelas equipes de saúde bucal da Estratégia Saúde da Família estavam relacionados com o município-polo da região de coalização partidária mais à esquerda, ao passo que o município-polo da região de coalização partidária mais à direita mostrou aumento expressivo na porcentagem de população potencialmente coberta por médicos. Em ambos os municípios-polo, a efetividade melhorou. Os achados confirmaram a noção de que as coalizações mais à esquerda aportam mais recursos em políticas sociais, mas encontram limites para superar desigualdades estruturais e converter suas preferências programáticas em politicas efetivas.

Sistemas de Saúde; Assistência Odontológica; Assistência Médica;

Fatores Politicos

\author{
Correspondência \\ J. D. B. Carneiro \\ Faculdade de Saúde Pública, Universidade de São Paulo. \\ Av. Dr. Arnaldo 715, São Paulo, SP 01246-904, Brasil. \\ joanadani9@gmail.com \\ 1 Faculdade de Saúde Pública, Universidade de São Paulo, São \\ Paulo, Brasil.
}




\section{Introdução}

No final da década de 1970, a descentralização foi uma das principais estratégias do processo de reforma dos Estados nacionais em decorrência da crise econômica mundial e esgotamento do Estado de Bem-Estar Social (Welfare State) ${ }^{1}$. No que pesem as críticas à descentralização, que estaria sujeita a interesses difusos de seus agentes, de difícil coordenação, podendo aumentar os contrastes regionais, a fragmentação e o abandono de responsabilidades sociais 2, diferentes correntes de orientação política, em vários países da Europa e também da América Latina, têm articulado propostas de descentralização a diversas expectativas de superação de problemas identificados no Estado e nos sistemas políticos nacionais. Passou-se a supor que formas descentralizadas de prestação de serviços públicos seriam mais responsivas às demandas sociais, fortaleceriam a democracia e seriam mais eficientes para elevar os níveis de bem-estar da população. Assim, reformas do Estado nessa direção seriam desejáveis, dado que viabilizariam a concretização de ideais progressistas, tais como equidade, justiça social, redução do clientelismo e aumento do controle social sobre o Estado 3 .

Diferentemente dos países europeus, que adotaram a descentralização regionalizada, no Brasil ela se deu a partir da transferência política, administrativa e financeira aos municípios. Apesar de tal estratégia ter assegurado a autonomia da gestão local e o acesso universal ao sistema, houve um estrangulamento financeiro em decorrência da maioria dos municípios não serem autossuficientes economicamente, mantendo-se a dependência financeira a estados e União 4,5. A estratégia da regionalização da saúde entrou tardiamente na agenda política, nos anos 2000. Um aspecto importante foi o esforço para se garantir segurança jurídica para as relações intergovernamentais na região de saúde, fortalecendo-se o papel dos estados no planejamento e cooperação intergovernamental no sentido da construção das redes de atenção à saúde (RAS) como peça viva do território 6 .

Ainda que os marcos institucionais do Sistema Único de Saúde (SUS), definidos na Constituição Federal de 1988 e nas Leis no 8.080 e no 8.142, de 1990, tenham sido operacionalizados sob a coalizão de centro-direita que sustentou os governos Fernando Henrique Cardoso, de 1995 a 2002, foi somente sob a coalizão de centro-esquerda dos governos Luiz Inácio Lula da Silva e Dilma Rousseff, de 2003 a 2014, que determinadas estratégias se expandiram de modo significativo a fim de atender a diretrizes de universalização, inclusão social e combate à desigualdade 7 .

A literatura sobre poder local tem enfatizado a importância das arenas e dos arranjos políticos locais para a conformação das estratégias de sobrevivência eleitoral e implementação de políticas públicas inovadoras 8 .

A existência de diferença ideológica entre partidos políticos é bastante analisada pela literatura. Parte dela sustenta que partidos de esquerda, considerados pró-welfare, quando no governo, gastam mais do que partidos de direita em políticas sociais, ao passo que países governados por partidos de direita têm os gastos nestas áreas reduzidos 7 .

Análise do processo político e de implementação das políticas na América Latina e Caribe mostrou que as variáveis políticas acrescentaram poder explicativo. Um forte histórico de democracia, equilíbrio partidário legislativo inclinado à esquerda e gastos com seguridade e assistência social associaram-se a níveis mais baixos de desigualdade na América Latina e Caribe 9.

Contudo outra vertente da literatura argumenta que partidos políticos fazem diferença, mas apenas moderadamente. Ou seja, mudanças na composição partidária do governo não estão associadas a mudanças instantâneas na orientação das políticas ${ }^{9}$. No governo, partidos encontram limites para converter suas preferências programáticas em ações de governo. Os resultados alcançados não decorrem automaticamente da ocupação do poder de Estado, pois coalizões de governo operam como freios à introdução de mudanças radicais no desenho das políticas 7 . Ainda que as evidências confirmem a relação da menor provisão de serviços públicos de saúde aos partidos de direita, a expansão da oferta pública de serviços não pode ser associada a nenhuma corrente ideológica particular, seja de direita ou de esquerda 8.

No Brasil, o esforço para superar os limites da municipalização da saúde e fortalecer o papel dos estados no planejamento regional tem resultado na organização de 438 regiões de saúde do país 10. Explorar a relação de variáveis políticas com as mudanças no aporte financeiro e na estrutura e desempenho de serviços públicos em regiões de saúde, situadas em polos extremos, pode indicar os 
limites e os alcances da orientação dos partidos políticos na expansão da oferta pública e na implementação das políticas de saúde.

O objetivo deste estudo foi descrever a orientação política da coalizão partidária, o aporte financeiro e os efeitos na estrutura e desempenho da assistência médica e odontológica nos municípios-polo de duas regiões de saúde brasileiras.

\section{Método}

Para atender ao objetivo, realizou-se um estudo de caso exploratório descritivo retrospectivo nas regiões de saúde Norte-Barretos e Juazeiro no período de 2007 a 2014. A região Juazeiro, situada ao norte do Estado da Bahia, é composta por dez municípios: Campo Alegre de Lourdes, Canudos, Casa Nova, Curaçá, Juazeiro, Pilão Arcado, Remanso, Sento Sé, Sobradinho e Uauá. Norte-Barretos, situada ao norte do Estado de São Paulo, também apresenta dez municípios em sua região: Altair, Barretos, Cajobi, Colina, Colômbia, Guaíra, Guaraci, Jaborandi, Olímpia e Severínia.

Essas regiões foram selecionadas intencionalmente porque apresentavam padrões distintos de condição socioeconômica e oferta de serviços, segundo a classificação formulada para as 438 regiões de saúde do país, pela pesquisa Política, Planejamento e Gestão das Regiões e Redes de Atenção à Saúde no Brasil 10. De acordo com a situação socioeconômica e oferta/complexidade dos serviços da saúde, as regiões foram distribuídas em cinco grupos, que variaram de alto, médio ou baixo desenvolvimento socioeconômico; e alta, média ou baixa oferta de serviços 11. A partir dessa tipologia, Juazeiro e Norte-Barretos apresentaram características socioeconômicas e na oferta de serviços opostas entre si, sendo posicionadas nos grupos 1 (baixo desenvolvimento socioeconômico e baixa oferta de serviços) e 5 (alto desenvolvimento socioeconômico e alta oferta de serviços) 11, respectivamente. Por esta razão, neste estudo, as regiões serão designadas como mais (Norte-Barretos) e menos desenvolvida (Juazeiro).

Enquanto numa região o Índice de Desenvolvimento Humano (IDH) e a renda domiciliar per capita, para 2010, eram 0,824 e R \$ 805,72, na outra eram, respectivamente, 0,677 e R \$331,90 12. Havia também contrastes em relação à oferta de serviços. Por exemplo, em 2014, a quantidade de leitos por mil/habitantes era 3,3 na região mais desenvolvida e 1,7 na menos desenvolvida; o número de unidades de pronto atendimento era 5 e 1; e o número de equipamentos de diagnóstico por imagem era 281 e 178 , respectivamente 12.

O intervalo temporal de 2007 a 2014 foi selecionado porque representou um período atravessado pela segunda e terceira fases do processo de regionalização, orientados respectivamente, pelo Pacto pela Saúde e pela Contratualização ${ }^{13}$. Além disso, os oito anos analisados atravessaram mais de uma gestão municipal e estadual em diferentes conjunturas políticas, permitindo a verificação de proposições de caráter mais estrutural.

Durante o período do estudo, a coalizão partidária foi definida pelas preferências eleitorais municipais e estaduais; intensidade da competição eleitoral nos municípios-polos e nos estados ${ }^{8}$. Foram utilizados apenas os dados do município-polo de cada região, porque é o ente que exerce significativa influência no desenho regional de saúde do território e é onde se encontra a maior disponibilidade de recursos de saúde.

Para medir as preferências nas eleições para prefeito e vereador dos municípios-polo, nos anos 2008 e 2012, e para governador, nos anos 2010 e 2014, realizou-se uma análise dos resultados obtidos pelos partidos agrupados no espectro ideológico esquerda-direita, conforme classificação estabelecida por Tarouco \& Madeira 14, e com base nos dados disponíveis no site do Tribunal Superior Eleitoral (TSE) 15 .

Para análise da intensidade da competição eleitoral, utilizou-se um "índice de segurança nas eleições presidenciais" para os estados nos quais as regiões se encontram (Bahia e São Paulo), baseado na diferença entre os resultados proporcionais das eleições presidenciais de 2010 e 2014 (\% de votos nos dois principais candidatos presidenciais, no primeiro e segundo turnos, subtraindo-se a diferença entre eles), também disponíveis no site do TSE 15. 
A orientação política dos partidos no espectro esquerda e direita foi determinada com base em uma classificação resultante de uma pesquisa com especialistas brasileiros que apresentou boa precisão e confiabilidade 14 .

$\mathrm{O}$ aporte financeiro foi medido por meio de indicadores per capita estabelecidos a partir da relação entre transferência financeira realizada pelo governo federal diretamente ao município e respectivo número de habitantes. Os repasses dizem respeito às transferências, entre 2007 e 2014, segundo critérios relativos ao bloco da atenção básica, composto pelo PAB Fixo e PAB Variável, e a subdivisão deste recurso especificamente para saúde bucal e saúde da família. Essa modalidade foi selecionada porque reflete uma política pública inovadora voltada à reorientação do modelo de atenção à saúde no Brasil tradicionalmente centrado na lógica hospitalar. As regiões de saúde foram representadas por seus respectivos municípios-polo pela influência que estes exercem no desenho regional da assistência à saúde, dada sua condição de centro técnico-administrativo do território e atração da demanda por assistência pública a serviços de saúde. A fonte dos dados foi o Portal da Transparência do governo federal 16 .

Os dados para a apuração dos indicadores de estrutura e desempenho da assistência médica e odontológica relativos a cada município-polo foram extraídos das fontes de dados: Cadastro Nacional de Estabelecimentos de Saúde (CNES) e Sistema de Informações Ambulatoriais (SIA) mantidos pelo Departamento de Informática do SUS (DATASUS) 17, para cada ano do período do estudo, ressalvadas algumas poucas exceções para códigos/procedimentos do SUS que sofreram descontinuidade em relação aos anos anteriores a 2008.

Os indicadores de estrutura foram número de médicos e número de cirurgiões-dentistas por 10 mil habitantes que atendem no SUS selecionados com base em estudos anteriores 18,19,20,21. Além disso, foram apurados o número de cirurgiões-dentistas por 10 mil habitantes que atuavam na atenção básica, a porcentagem de população total potencialmente coberta pela equipe de saúde bucal (ESB) da Estratégia Saúde da Família (ESF) e porcentagem de cobertura de equipes de atenção básica.

Os indicadores de desempenho relativo à efetividade foram: número de consultas médicas na atenção básica; número de procedimentos odontológicos básicos individuais, todos padronizados por 100 habitantes; e cobertura de ação coletiva de escovação dental supervisionada para população de 5 a 14 anos selecionados com base em estudos anteriores 18,22 .

A interpretação dos dados se deu com o auxílio de planilhas criadas pelo programa Excel (https:// products.office.com/), além dos dados históricos e socioeconômico-epidemiológicos e políticos das regiões comparadas. Este estudo fez uso de dados secundários, disponíveis publicamente.

\section{Resultados}

A Tabela 1 traz os resultados dos indicadores das preferências eleitorais. Em Norte-Barretos, de 2008 para 2012, partidos mais inclinados à direita apresentaram decréscimo de votos, enquanto aqueles mais inclinados à esquerda apresentaram aumento. Em Juazeiro, tanto quadros à direita quanto à esquerda apresentaram crescimento, com maior destaque para esquerda. Ainda que tenha sido notado um ligeiro aumento nos quadros à esquerda, observou-se que os quadros de perfil ideológico mais à direita, considerando prefeitos ou vereadores, estavam, em sua maioria, na região mais desenvolvida, ao passo que aqueles mais à esquerda estavam na região menos desenvolvida.

A Tabela 2 apresenta os indicadores das preferências eleitorais e intensidade da competição eleitoral estaduais de 2010 a 2014. Para preferências eleitorais, o estado ao qual o município-polo da região mais desenvolvida pertence, São Paulo, apresentou maior preferência pela direita, incluindo aumento no período; enquanto o estado onde o município-polo da região menos desenvolvida se encontra, Bahia, a maior preferência foi pela esquerda, mas com queda no período. Em relação à intensidade da competição eleitoral, o padrão "orientação à direita para São Paulo" e "orientação à esquerda para Bahia” se manteve. Chamou atenção a diferença entre os dois principais candidatos que disputaram a presidência. Para Bahia, a vantagem da orientação à coalizão de centro-esquerda se manteve em pouco mais de $80 \%$, enquanto a orientação à centro-direita para São Paulo apresentou uma vantagem em torno de 11\% em 2010, aumentando para 47\% em 2014. 


\section{Tabela 1}

Preferências eleitorais nos municípios-polo das regiões de saúde, 2008 e 2012.

\begin{tabular}{|c|c|c|c|c|}
\hline \multirow[t]{2}{*}{ Preferências eleitorais municipais } & \multicolumn{2}{|c|}{ Municípios-polo da região mais desenvolvida } & \multicolumn{2}{|c|}{ Municípios-polo da região menos desenvolvida } \\
\hline & Partidos & \% de votos válidos & Partidos & \% de votos válidos \\
\hline \multicolumn{5}{|l|}{2008} \\
\hline Prefeito & PTB & 73,9 & PCdoB & 38,2 \\
\hline Vereadores eleitos pela direita & $\begin{array}{l}\text { PMDB, PTB, PP, PPS, } \\
\text { DEM, PSDB, PR }\end{array}$ & 29,0 & PSDB, PMDB, PSL, PTB & 12,1 \\
\hline Vereadores eleitos pela esquerda & PT, PV, PDT & 8,1 & PT, PCdoB, PV, PTdoB & 14,9 \\
\hline \multicolumn{5}{|l|}{2012} \\
\hline Prefeito & PSDB & 57,0 & PCdoB & 54,6 \\
\hline Vereadores eleitos pela direita & $\begin{array}{c}\text { PPS, PR, PSDB, PMDB, } \\
\text { PTB, DEM }\end{array}$ & 22,7 & $\begin{array}{c}\text { PSDB, PP, PR, DEM, PTC, } \\
\text { PSD, PTB }\end{array}$ & 16,4 \\
\hline Vereadores eleitos pela esquerda & PDT, PV, PCdoB, PT & 14,7 & $\begin{array}{c}\text { PT, PV, PTdoB, PCdoB, } \\
\text { PDT, PSB }\end{array}$ & 21,6 \\
\hline
\end{tabular}

Partidos: DEM: Democratas; PCdoB: Partido Comunista do Brasil; PDT: Partido Democrático Trabalhista; PMDB: Partido do Movimento Democrático Brasileiro; PP: Partido Progressista; PPS: Partido Popular Socialista; PR: Partido da República; PSB: Partido Socialista Brasileiro; PSD: Partido Social Democrático; PSDB: Partido da Social Democracia Brasileira; PSL: Partido Social Liberal; PT: Partido dos Trabalhadores; PTB: Partido Trabalhista Brasileiro; PTC: Partido Trabalhista Cristão; PV: Partido Verde.

Fonte: Tribunal Superior Eleitoral (TSE) 15.

\section{Tabela 2}

Preferências eleitorais e intensidade da competição eleitoral, estados das regiões de saúde, 2010 e 2014.

\begin{tabular}{ll}
\hline $\begin{array}{l}\text { Preferências eleitorais estaduais } \\
\text { Estado da região menos } \\
\text { desenvolvida }\end{array}$ & $\begin{array}{c}\text { Estado da região mais } \\
\text { desenvolvida }\end{array}$ \\
$\begin{array}{l}\text { Governador eleito } \\
2010 \text { (\% de votos válidos) }\end{array}$ & PT (68,8\%) PT (54,5\%) \\
$\begin{array}{l}\text { Intensidade da competição eleitoral } \\
2010 \text { (diferença \% entre 1o e } 2 \text { o turnos para o partido vencedor) }\end{array}$ & PT (83,3\%) \\
2014 (diferença $\%$ entre 1o e 2 o turnos para o partido vencedor) & PT (83,5\%) \\
\hline
\end{tabular}

Partidos: PSDB: Partido da Social Democracia Brasileira; PT: Partido dos Trabalhadores.

Fonte: Tribunal Superior Eleitoral (TSE) ${ }^{15}$.

A Tabela 3 apresenta os indicadores de aplicação financeira de recursos entre 2007 e 2014 para atenção básica per capita relativos ao PAB, saúde bucal e saúde da família. Em toda série temporal, o município-polo da região menos desenvolvida apresentou indicadores mais elevados, de duas a seis vezes maior, a depender do ano de análise. Para saúde bucal, o repasse per capita só começou a acontecer em 2010, na região mais desenvolvida, enquanto na região menos desenvolvida foram identificados repasses desde 2007.

Na Tabela 4 são apresentados os valores dos indicadores de estrutura e efetividade da assistência médica e odontológica. Em relação à estrutura, é possível observar que houve aumento do número de médicos e de dentistas vinculados ao SUS nos dois municípios-polo, mas este aumento foi mais expressivo na região mais desenvolvida. Entretanto a cobertura da atenção básica e a porcentagem da população potencialmente coberta pela ESB teve aumento expressivo no município-polo da região menos desenvolvida. Dentre os indicadores de efetividade, houve aumento no número de consultas 


\section{Tabela 3}

Indicadores per capita segundo repasse por blocos de financiamento da atenção básica (PAB Fixo + PAB Variável; saúde bucal; saúde da família). municípios-polo das regiões de saúde, 2007 a 2014.

\begin{tabular}{|c|c|c|c|c|c|c|}
\hline \multirow[t]{2}{*}{ Ano } & \multicolumn{3}{|c|}{ Municípios-polo da região mais desenvolvida } & \multicolumn{3}{|c|}{ Municípios-polo da região menos desenvolvida } \\
\hline & $\begin{array}{c}\text { PAB (Fixo + Variável) } \\
\text { per capita }(\mathrm{R} \$)\end{array}$ & $\begin{array}{l}\text { Saúde bucal per } \\
\text { capita }(\mathrm{R} \$)\end{array}$ & $\begin{array}{l}\text { Saúde da família } \\
\text { per capita }(\mathrm{R} \$)\end{array}$ & $\begin{array}{c}\text { PAB (Fixo + Variável) } \\
\text { per capita }(\mathrm{R} \$)\end{array}$ & $\begin{array}{c}\text { Saúde bucal } \\
\text { per capita }(\mathrm{R} \$)\end{array}$ & $\begin{array}{c}\text { Saúde da família } \\
\text { per capita (R\$) }\end{array}$ \\
\hline 2007 & 18,8 & 0,0 & 2,2 & 43,0 & 3,8 & 15,3 \\
\hline 2008 & 20,9 & 0,0 & 3,0 & 48,3 & 4,1 & 14,5 \\
\hline 2009 & 21,7 & 0,0 & 3,7 & 52,5 & 4,3 & 15,3 \\
\hline 2010 & 25,6 & 0,9 & 4,1 & 73,8 & 5,8 & 20,9 \\
\hline 2011 & 28,5 & 1,0 & 4,0 & 84,9 & 6,0 & 21,4 \\
\hline 2012 & 43,8 & 1,2 & 4,8 & 93,8 & 6,9 & 24,7 \\
\hline 2013 & 36,3 & 1,4 & 5,5 & 84,0 & 5,5 & 18,7 \\
\hline 2014 & 43,3 & 1,4 & 5,3 & 86,7 & 5,1 & 18,2 \\
\hline
\end{tabular}

Fonte: Portal da Transparência 16.

\section{Tabela 4}

Indicadores de estrutura e efetividade nos municípios-polo das regiões de saúde, 2007-2014.

\begin{tabular}{|c|c|c|}
\hline Dimensão & $\begin{array}{l}\text { Municípios-polo da região mais } \\
\text { desenvolvida }\end{array}$ & $\begin{array}{l}\text { Municípios-polo da região } \\
\text { menos desenvolvida }\end{array}$ \\
\hline \multicolumn{3}{|l|}{ Estrutura } \\
\hline Número de médicos no SUS/10 mil habitantes & Aumento de 3,8 para 10,6 & Aumento de 4,3 para 7,7 \\
\hline Cobertura das equipes de atenção básica & Aumento de $48,9 \%$ para $51,1 \%$ & Aumento de $49,8 \%$ para $64,5 \%$ \\
\hline População potencialmente coberta pela ESB na ESF & Aumento de $11,5 \%$ para $13 \%$ & Aumento de $65,4 \%$ para $77,8 \%$ \\
\hline Número de dentistas que atendem no SUS/10 mil habitantes & Variação: 7,9 a 8,3 & Variação: 2,7 a 3,9 \\
\hline Número de dentistas que atuam na atenção básica/10 mil habitantes & Variação: 5,6 a 6,5 & Variação: 1,6 a 2,8 \\
\hline \multicolumn{3}{|l|}{ Efetividade } \\
\hline Número de consultas médicas na atenção básica/100 habitantes & Variação: 8,6 a 11,5 & Variação: 5,9 a 7,8 \\
\hline $\begin{array}{l}\text { Cobertura da ação coletiva de escovação dental supervisionada, } \\
\text { população } 5 \text { a } 14 \text { anos }\end{array}$ & Variação: $13,9 \%$ a $27,1 \%$ & Variação: $4,0 \%$ a $15,3 \%$ \\
\hline Número de procedimentos odontológicos básicos/100 habitantes & Variação: 5,0 a 7,2 & Variação: 1,2 a 5,5 \\
\hline
\end{tabular}

ESB: equipe de saúde bucal; ESF: Estratégia Saúde da Família; SUS: Sistema Único de Saúde.

Fonte: elaboração própria.

médicas por 100 habitantes, na cobertura da ação coletiva de escovação dental supervisionada em população 5 a 14 anos e no número de procedimentos odontológicos básicos/100 habitantes em ambos os municípios-polo das regiões de saúde.

\section{Discussão}

A orientação política dos partidos de coalizão, o aporte financeiro e a estrutura/desempenho da assistência médica e odontológica em dois municípios-polo de duas regiões de saúde brasileiras foram descritos retrospectivamente. Entre 2007 e 2014, os resultados mostraram maior aporte financeiro per capita (PAB, saúde bucal, saúde da família) e maior porcentagem de população potencialmente coberta pela atenção básica e pelas ESB da ESF no município-polo da região menos desenvolvida. 
Por outro lado, o município-polo da região mais desenvolvida mostrou um aumento expressivo na porcentagem de população potencialmente coberta por médicos. Em ambos os municípios-polo, a efetividade melhorou. A coalizão partidária e as preferências eleitorais foram marcadamente distintas entre os municípios-polo. Enquanto o município-polo da região mais desenvolvida esteve sob dominância política de uma coalizão mais à direita, o município-polo da região menos desenvolvida foi atravessado por uma inclinação mais à esquerda.

Estudo anterior que avaliou as mudanças ocorridas no âmbito das duas regiões de saúde como um todo encontrou maior cobertura médica na região mais desenvolvida e maiores coberturas da atenção básica e de ESB na ESF para região menos desenvolvida, padrão similar aos municípios-polo aqui descritos. Esse padrão estaria associado às características do processo de regionalização e à trajetória política de cada modalidade de assistência considerando o efeito silos 13 . A criação de redes regionais de serviços sem a adoção de critérios prévios de planejamento e a atribuição de responsabilidades muito amplas para um nível de governo com capacidade limitada representariam pontos críticos para o desenvolvimento das RAS 23 . Além disso, diferenças decorrentes da trajetória política que tem marcado a assistência médica e a assistência odontológica teriam exercido importante influência sobre o grau de equivalência com que ambos os serviços se estruturaram no processo de regionalização da saúde 13 .

Em relação ao aporte financeiro, os resultados mostraram que o aporte relativo ao bloco da atenção básica, tanto para saúde bucal quanto para saúde da família, foi sempre mais favorável à região menos desenvolvida na qual predominaram coalizações partidárias mais à esquerda, reconhecidas na literatura por elevar os recursos financeiros aplicados em políticas sociais 7 . Por outro lado, a relativa manutenção das diferenças entre os municípios-polo nos valores dos indicadores de estrutura e efetividade apresentados confirma a noção de que coalizações mais à esquerda encontram limites para superar desigualdades estruturais e converter suas preferências programáticas em políticas efetivas 7 .

No município-polo da região mais desenvolvida, pertencente ao Estado de São Paulo, houve predominância de orientação mais à direita, especialmente pelo Partido da Social Democracia Brasileira (PSDB), o qual garantiu vitória para governo e maioria de votos para o seu candidato à presidência. Por outro lado, no município-polo da região menos desenvolvida, pertencente ao Estado da Bahia, predominaram votos e desfechos mais favoráveis à esquerda, com vitória do Partido dos Trabalhadores (PT) tanto para governo quanto para presidência.

Cabe destacar que o governo federal esteve sob coalizações orientadas por dois partidos, PSDB e PT, de 1995 a 2014. As duas siglas que também foram as que mais cresceram em termos de representação parlamentar e capilaridade no território nacional, diferenciam-se em seus espectros ideológicos: enquanto o PT, apesar das concessões ao centro, se manteve inclinado à esquerda, o PSDB deslocouse do centro (1995-2002) para a direita (2003-2014) 24. Tal variação representou uma tendência de estratificação do voto nas eleições presidenciais, a qual influenciou a dinâmica das decisões estaduais e municipais, com aumento de apoio ao PT, a partir de 2002, na porção do eleitorado com menor renda média, e manutenção da concentração da popularidade do PSDB entre os eleitores de maior renda média. Assim, o PT preservou sua agenda de políticas de proteção social, para se manter próximo das preferências de um eleitorado de menor renda; e o PSDB alterou seu comportamento legislativo e se distanciou da agenda de proteção social, com o objetivo de espelhar a preferência do eleitorado nos estratos superiores de renda 24 . Embora este trabalho não tenha avaliado as preferências eleitorais a partir dos estratos de renda, tal tendência pode auxiliar na explicação das preferências esquerda-direita nas regiões estudadas, as quais guardam importantes diferenças socioeconômicas entre si.

Na América Latina, e no Brasil, existem partidos com identidades ideológicas e apelos de classe distintos e uma boa parte dos cidadãos tem atribuído significado relevante à dimensão esquerdadireita para estruturação da política 25. Pesquisa realizada em 2004 25, para 17 países latinos-americanos, demonstrou que a média de $78 \%$ dos cidadãos era capaz de se colocar na escala esquerda-direita. A esquerda se manteve hegemônica no município-polo da região menos desenvolvida e, apesar de não ter vencido as eleições no município-polo da região mais desenvolvida, ela se manteve competitiva, especialmente a partir de 2010, quando o PT confirmou sua vitória na reeleição para presidência. Ainda que tenha sofrido mudanças, o PT manteve certo traço programático desde o início, e seu crescente sucesso eleitoral até 2014 pode ter desencadeado certo "contágio à esquerda", durante o período investigado neste estudo de caso, um fenômeno também observado nos sistemas partidários 
europeus no surgimento da política de massa por lá. Enquanto os partidos de oposição de esquerda se consolidaram como organizações e demonstraram fortes compromissos programáticos, os partidos de centro e direita foram forçados a seguir o exemplo, em certa medida, no fortalecimento de suas organizações e perfis programáticos 26.

Estudo mostrou que as percepções e preferências do eleitorado brasileiro se diferenciavam em relação às propostas do PT e PSDB acerca da mobilidade e proteção social 24. Enquanto o eleitorado petista, em sua maioria indivíduos de menor renda, tenderia a dar suporte à adoção de políticas de proteção social, o grupo de maior renda média, que concentra seu apoio eleitoral em torno do PSDB, seria mais resistente à redistribuição. Entre 2007 e 2014, na região menos desenvolvida, os indicadores de estrutura apresentaram um crescimento mais expressivo se comparados à região mais desenvolvida, especialmente a cobertura da atenção básica e cobertura de ESB na ESF.

$\mathrm{O}$ aporte financeiro medido pela transferência do PAB per capita foi duas vezes maior no município-polo da região menos desenvolvida. Grande parte dessa diferença pode ser atribuída à fração variável do PAB que depende da incorporação de novas estratégias pelos entes municipais voltadas à qualificação da atenção à saúde (saúde da família, saúde bucal, vigilância, agentes comunitários etc.) 27,28 , sugerindo uma forte indicação do caráter inovador da coalizão mais à esquerda, que exerceu dominância nesta região.

De modo distinto, na região mais desenvolvida, o repasse per capita para saúde bucal na atenção básica ocorreu mais tardiamente. Um importante efeito do desenvolvimento da saúde bucal no SUS foi a realocação de recursos odontológicos de unidades escolares para unidades de saúde, reorientando a atenção básica e criando condições para maior integração das ações de saúde bucal nas políticas do setor ${ }^{29}$. No entanto este deslocamento de recursos não é realizado sem conflitos e pode ser mais lento ou mais rápido, dependendo dos interesses dominantes da coalizão política em cada contexto.

Em que pese a autonomia política e administrativa do município, o conteúdo das políticas locais no Brasil é muito afetado pela política federal. Desse modo, alguns resultados encontrados podem refletir não apenas escolhas locais, mas também as opções de indução federal. No processo de ampliação da atenção básica, foi fundamental a criação do PAB que suprimiu o pagamento por produção de serviços e fixou as transferências financeiras segundo critérios populacionais 27 . O ente federal detém a maior parte das fontes de recursos para saúde e contribui com 45,5\% dos repasses para municípios. No período do estudo, os recursos federais para atenção básica aumentaram de 17,1\% para 20,3\%, ao passo que os recursos para média e alta complexidade sofreram queda de 50,5\% para 47,3\% 28,30.

O fato de a região menos desenvolvida reorientar seu modelo assistencial para atenção básica, em linha com as políticas de indução do governo federal, também pode estar associado a um alinhamento programático da agenda política, tendo em vista que os governos federal, estadual e municipal estavam localizados no mesmo campo ideológico (centro-esquerda). As variáveis políticas relativas ao município-polo da região mais desenvolvida estavam alinhadas mais à direita, em uma posição mais refratária à influência do governo federal e de suas políticas de indução e estratégias de qualificação da atenção à saúde promovidas por meio do PAB per capita.

Os indicadores de estrutura, especialmente os que medem a cobertura de equipes de atenção básica, ESB da ESF e o número de médicos por 10 mil habitantes, podem indicar maior ou menor ênfase a políticas de bem-estar, especialmente no aspecto sanitário, pois houve uma crescente ampliação na oferta desses serviços sob coalizações de centro-esquerda no Brasil. A expansão do provimento de médicos se deu em todo país, a partir da criação do Programa Mais Médicos (PMM) em 2013. A Região Nordeste foi a mais beneficiada. Observou-se redução da escassez desses profissionais e aumento das consultas médicas 31. Embora esta não seja a região com maior desigualdade territorial destes profissionais (fica atrás da Região Norte) 31, do ponto de vista político-partidário, o Nordeste foi a região na qual coalizações mais à esquerda venceram em todos os estados para presidência. $\mathrm{Na}$ região menos desenvolvida, o prefeito do município-polo liderava uma coalizão mais à esquerda, e os vereadores deste espectro tiveram mais votos. Nesta região, o percentual de médicos do PMM era 14,3\% em 2014, enquanto na região mais desenvolvida não chegava a 0,5\% 12 .

A expansão da ESB na ESF aconteceu similarmente ao que houve com os médicos. A cobertura estimada foi mais elevada para o município-polo da região menos desenvolvida. Com a Política Nacional de Saúde Bucal (PNSB), a atenção à saúde bucal passou a compor uma das prioridades do governo federal impulsionando a implantação e expansão das ESB, especialmente na Região Nordes- 
te 32,33. A PNSB foi lançada em 2004, um ano após o início do primeiro governo composto por uma coalizão de centro-esquerda no Brasil. Dentre as diretrizes, destacavam-se a expansão de ESB na ESF, organização da atenção especializada em saúde bucal por meio da criação dos Centros de Especialidades Odontológicas (CEO) e dos Laboratórios Regionais de Próteses Dentárias (LRPD) 32.

A PNSB prevê uma concepção de atenção à saúde bucal centrada na integralidade do cuidado, na família, na comunidade e no território, a partir de ações com enfoque interdisciplinar e ampliado para enfrentar os determinantes não biológicos das doenças bucais 33. Tal aspecto pode auxiliar na explicação do aumento do indicador de cobertura de ação coletiva dental supervisionada em ambas as regiões.

O Programa Brasil Sorridente (PBS), instituído em 2004, teve abrangência nacional, com maior ou menor ênfase, dependendo das relações políticas entre os entes federativos dos três níveis de governo. Ele contou com um volume inédito de recursos que permitiu, dentre outras coisas, a implementação e expansão de ESB na atenção básica. Embora a ESB tenha sido iniciativa do governo Fernando Henrique Cardoso, os recursos para manutenção dessa estratégia foram ampliados sob a coalizão de centro-esquerda, passando de R \$689,9 milhões em média, entre 1995 e 2002, para cerca de R \$1,05 bilhão em média, entre 2003 e 2013, um aumento nominal de 51,5\% 34 .

Os resultados deste estudo de caso confirmaram a ideia de que gastos com saúde, sob coalizações políticas inclinadas mais à esquerda, no poder por longos períodos, tendem não apenas a serem maiores, mas também produzir efeitos redistributivos, uma proposição corroborada por alguns especialistas 35 . No município-polo da região menos desenvolvida, uma coalizão de centro-esquerda se manteve no poder no período analisado, concomitante a coalizações de mesmo tipo na esfera estadual e federal. Tal aspecto pode auxiliar na explicação da maior expansão de médicos, assim como em maior ampliação da atenção básica e ESB na ESF. Por outro lado, o impacto foi tardio no município-polo da região mais desenvolvida, cuja coalizão estava inclinada mais à direita. Os partidos políticos diferem em suas visões de mundo e compromissos com a redistribuição e seus apelos correspondentes ao eleitorado. Entretanto, onde a esquerda se mantém competitiva, é esperado que a direita incorpore pautas tradicionalmente defendidas pela esquerda 9 (como maior investimento em seguridade, assistência social e sanitária) para atrair o eleitorado. Em outras palavras, espera-se que o equilíbrio partidário de poder forme uma variedade de políticas que afetem a desigualdade (redução) a médio e longo prazo 9. É importante destacar que, no Brasil, cerca de 104 milhões de brasileiros (quase metade da população), vivem com o equivalente a meio salário-mínimo 36 . Assim, a expansão de políticas sociais interessa tanto aos partidos de esquerda quanto de direita, dado o elevado peso do eleitorado dependente de serviços públicos estatais.

Cabe destacar que a democracia é o pré-requisito para que governos, sob diferentes coalizações partidárias, se distingam em termos de política social, porque abre a possibilidade de governos mais responsivos às pressões dos cidadãos ou da concorrência partidária com base em promessas de melhoria da política social e sanitária 26 .

Em relação às limitações deste estudo, alguns aspectos precisam ser comentados. Os indicadores selecionados para este estudo são de fontes secundárias e devem ser considerados com cautela. $\mathrm{O}$ indicador referente à análise da força de trabalho foi direcionado para os profissionais com vínculo ao SUS tanto na assistência médica quanto na odontológica, a fim de evitar problemas de sub/sobrerregistro derivados de dados provenientes de conselhos de exercício profissional. A análise abrangendo um período largo, como a adotada neste estudo, contribui para atenuar a instabilidade dos registros. Em relação à seleção das regiões de saúde, ela se deu de forma intencional por conta da elevada diferença na condição socioeconômica (PIB per capita, renda domiciliar per capita e escolaridade) e da oferta de serviços de saúde (internações de alta complexidade/mil habitantes e quantidade de leitos/ mil habitantes). Apesar de o estudo de caso auxiliar na compreensão de fenômenos individuais, organizacionais, sociais e políticos, estabelecendo a relação entre o fenômeno-contexto ${ }^{37}$, a generalização dos resultados é um fator limitante deste método.

Em 2017, uma coalizão conservadora passou a dar sustentação ao governo, e a agenda política se deslocou para a direita do espectro ideológico. Com isso, uma emenda constitucional de teto de gastos públicos foi aprovada, alterando o regime fiscal e impondo um horizonte de 20 anos de perdas progressivas de receita vinculadas às políticas públicas de proteção social ${ }^{38}$. Desta forma, projeta-se um processo progressivo de desfinanciamento do SUS em oposição ao período anterior de orientação 
mais à esquerda, o que poderá comprometer a manutenção dos serviços de saúde e a qualidade da resposta às necessidades de saúde da população.

Os achados apontaram que a efetividade melhorou em ambos os municípios-polo, ao passo que a estrutura apresentou padrão misto: percentual de população potencialmente coberta por médicos mais elevado para o município localizado na região mais desenvolvida, e porcentagem de população potencialmente coberta por ESB e equipes de atenção básica mais alto no município pertencente à região menos desenvolvida. $\mathrm{O}$ aporte financeiro para atenção básica, seja para saúde da família ou saúde bucal, foi sempre mais elevado para o município da região menos desenvolvida, cujas preferências eleitorais e coalizão partidária localizaram-se mais à esquerda, ao passo que o município da região mais desenvolvida apresentou preferências eleitorais e coalizão partidária mais à direita. Tais achados são compatíveis com a literatura que sustenta maior aporte de recursos em políticas sociais sob governos de esquerda que encontram limites para superar desigualdades estruturais e converter suas preferências programáticas em políticas efetivas. Estudos mais abrangentes são necessários para confirmação destas proposições.

\section{Colaboradores}

J. D. B. Carneiro e P. Frazão contriubuíram com a concepção e projeto do estudo, análise e interpretação dos dados, redação e revisão crítica do conteúdo intelectual. A. E. M. Bousquat contribuiu com a análise e interpretação dos dados e revisão crítica relevante do conteúdo intelectual. Todos os autores aprovaram a versão final a ser publicada e são responsáveis por todos os aspectos do trabalho na garantia de exatidão e integridade de qualquer parte da obra.

\section{Informações adicionais}

ORCID: Joana Danielle Brandão Carneiro (00000003-3629-8091); Aylene Emilia Moraes Bousquat (0000-0003-2701-1570); Paulo Frazão (0000-00023224-0020).

\section{Agradecimentos}

Agradecemos à Coordenação de Aperfeiçoamento de Pessoal de Nível Superior (CAPES) por auxiliar no fomento à pesquisa, custeando uma bolsa de doutorado a uma das autoras.

\section{Referências}

1. Pereira AMM, Lima LD, Machado CV, Freire JM. Descentralização e regionalização em saúde na Espanha: trajetórias, características e condicionantes. Saúde Debate 2015; 39(n. esp.):11-27.

2. Guimarães L, Giovanella L. Entre a cooperação e a competição: percursos da descentralização do setor saúde no Brasil. Rev Panam Salud Pública 2004; 16:283-8.

3. Arretche MTS. O mito da descentralização: maior democratização e eficiência das políticas públicas? Rev Bras Ciênc Soc 1996; 31:44-66.

4. Viana ALD, Lima LD, Oliveira RG. Descentralização e federalismo: a política de saúde em novo contexto - lições do caso brasileiro. Ciênc Saúde Colet 2002; 7:493-507.

5. Santos L, Campos GWS. SUS Brasil: a região de saúde como caminho. Saúde Soc 2015; 24:438-46.

6. Albuquerque MV, Viana ALD. Perspectivas de região e redes na política de saúde brasileira. Saúde Debate 2015; 39(n.esp.): 28-38.

7. Arretche M, Marques E, Faria CAP. Introdução. In: Arretche M, Marques E, Faria CAP, organizadores. As políticas da política: desigualdades e inclusão nos governos do PSDB e do PT. São Paulo: Editora Unesp; 2019. p. 1-20.

8. Arretche MTS, Marques E. Municipalização da saúde no Brasil: diferenças regionais, poder do voto e estratégias de governo. Ciênc Saúde Colet 2002; 7:455-79. 
9. Huber E, Pribble J, Nielson F, Stephens JD. Politics and Inequality in Latin America and the Caribbean. Am Sociol Rev 2006; 71:94363.

10. Viana ALD, Bousquat A, Pereira APCM, Uchimura LYT, Albuquerque MV, Mota PHS, et al. Tipologia das regiões de saúde: condicionantes estruturais para a regionalização no Brasil. Saúde Soc 2015; 24:413-22.

11. Albuquerque MV, Viana ALD, Lima LD, Ferreira MP, Fusaro ER, Iozzi FL. Desigualdades regionais na saúde: mudanças observadas no Brasil de 2000 a 2016. Ciênc Saúde Colet 2017; 22:1055-64.

12. Região e Redes. Banco de indicadores regionais e tipologia. https://www.resbr.net.br/ (acessado em 14/Dez/2020).

13. Carneiro JDB, Bousquat A, Chaves SCL, Frazão P. Estrutura e desempenho da assistência médica e odontológica em duas regiões de saúde brasileiras entre 2007 e 2014. Ciênc Saúde Colet 2020; 26 Suppl 2:3555-66.

14. Tarouco GS, Madeira RM. Os partidos brasileiros segundo seus estudiosos - análise de um expert survey. Civitas 2015; 15:24-39.

15. Tribunal Superior Eleitoral. Eleições anteriores. https://www.tse.jus.br/eleicoes/eleicoesanteriores (acessado em 10/Dez/2020).

16. Portal da Transparência. Aplicação em saúde. http://aplicacao.saude.gov.br/portaltransparencia (acessado em 12/Nov/2020).

17. Departamento de Informática do SUS. Tabnet. https://datasus.saude.gov.br/informacoes-desaude-tabnet/ (acessado em 10/Out/2020).

18. Castro ALB, Andrade CLT, Machado CV, Lima LD. Condições socioeconômicas, oferta de médicos e internações por condições sensíveis à atenção primária em grandes municípios do Brasil. Cad Saúde Pública 2015; 31:2353-66.

19. Girardi S, Carvalho CL, Wan Der Maas L, Farah J, Freire JA. O trabalho precário em saúde: tendências e perspectivas na Estratégia da Saúde da Família. Saúde Debate 2010; 45:11-23.

20. Jaccottet CMG, Barros AJD, Camargo MBJ, Cascaes AM. Avaliação das necessidades de tratamento odontológico e da capacidade produtiva da rede de atenção básica em saúde bucal no município de Pelotas, estado do Rio Grande do Sul, Brasil, 2009. Epidemiol Serv Saúde 2012; 21:333-40.

21. Cascaes AM, Dotto L, Bonfim RA. Tendências da força de trabalho de cirurgiões-dentistas no Brasil, no período de 2007 a 2014: estudo de séries temporais com dados do Cadastro $\mathrm{Na}$ cional de Estabelecimentos de Saúde. Epidemiol Serv Saúde 2018; 27:e201723615.

22. Fernandes JKB, Pinho JRO, Queiroz RCS, Thomaz EBAF. Avaliação dos indicadores de saúde bucal no Brasil: tendência evolutiva pró-equidade? Cad Saúde Pública 2016; 32:e00021115.

23. Vargas I, Mogollón-Perez AS, Unger JP, da Silva MRF, De Paepe P, Vázques ML. Regionalbased Integrated Healthcare Network policy in Brazil: from formulation to practice. Health Policy Plan 2014; 30:705-17.
24. Araújo V, Flores P. Competição eleitoral e ideologia partidária: PT, PSDB e a agenda de proteção social no Brasil (1991-2014). In: Arretche M, Marques E, Faria CAP, organizadores. As políticas da política: desigualdades e inclusão nos governos do PSDB e do PT. São Paulo: Editora Unesp; 2019. p. 23-48.

25. Colomer JM, Escatel LE. The left-right dimension in Latin America. México DF: Centro de Investigación y Docencia Económicas; 2004. (Working Paper SDTEP, 165).

26. Huber E, Stephens JD. Theoretical framework and methodological approach. In: Huber E, Stephens JD, organizadores. Democracy and the left. Social policy and inequality in Latin America. Chicago: University of Chicago Press; 2013. p. 13-52.

27. Solla JJSP, Reis AAC, Soter APM, Fernandes AS, Palma JJL. Mudanças recentes no financiamento federal do Sistema Único de Saúde: atenção básica à saúde. Rev Bras Saúde Mater Infant 2007; 7:495-502.

28. Mendes A, Marques RM. O financiamento da atenção básica e da Estratégia Saúde da Família no Sistema Único de Saúde. Saúde Debate 2014; 38:900-16.

29. Frazão P, Narvai PC. Saúde bucal no Sistema Único de Saúde: 20 anos de lutas por uma política pública. Saúde Debate 2009; 33:64-71.

30. Mendes A, Carnut L, Guerra LDS. Reflexões acerca do financiamento federal da atenção básica no Sistema Único de Saúde. Saúde Debate 2018; 42(n.esp.1):224-43.

31. Netto JJM, Rodrigues ARM, Aragão OC, Goyanna NF, Cavalcante AES, Vasconcelos MAS, et al. Programa Mais Médicos e suas contribuições para a saúde no Brasil: revisão integrativa. Rev Panam Salud Pública 2018; 42:e2.

32. Scarparo A, Zermiani TC, Ditterich RG, Pinto MHB. Impacto da Política Nacional de Saúde Bucal - Programa Brasil Sorridente - sobre a provisão de serviços odontológicos no Estado do Rio de Janeiro. Cad Saúde Colet (Rio J.) 2015; 23:409-15.

33. Pinho JRO, Souza TC, Vilas Bôas MD, Neves PAM. Evolução da cobertura das equipes de saúde bucal nas macrorregiões brasileiras. Rev Assoc Paul Cir Dent 2015; 69:80-5.

34. Cristo CS, Mendes AN, Frazão P, Narvai PC. Gasto federal com ações de saúde bucal no Sistema Único de Saúde no período de 1995 a 2013. Tempus (Brasília) 2020; 14:103-14.

35. Batista C. Partidos políticos, ideologia e política social na América Latina: 1980-1999. Dados Rev Ciênc Soc 2008; 51:647-86.

36. Mendonça $H$. Viver com 413 reais por mês, a realidade da metade do Brasil. El País 2019; 4 nov. https://brasil.elpais.com/brasil/2019/ 10/30/economia/1572454880_959970.html.

37. Yin RK. Estudo de caso: planejamento e métodos. 2a Ed. Porto Alegre: Bookman; 2001.

38. Promulgada Emenda Constitucional do Teto de Gastos Públicos. Senado Notícias 2016; 15 dez. https://www12.senado.leg.br/noticias/ materias/2016/12/15/promulgada-emendaconstitucional-do-teto-de-gastos. 


\section{Abstract}

Various government coalitions encounter limits when attempting to implement policy changes. The study aimed to describe the policy orientation of party coalitions, budget outlay, and the structure and performance of medical and dental care in two health regions of Brazil with different socioeconomic conditions and supplies of services. The indicators used were based on official data from 2007 and 2014 and characteristics of the party coalition defined by municipal electoral preferences and the intensity of electoral competition in each state of the respective major geographic region. Higher per capita budget outlay and higher percentage of the population potentially covered by primary care and by the oral health teams under the Family Health Strategy were related to the regional hub municipality with a more left-leaning party coalition, while the regional hub municipality with the more right-leaning party coalition showed an important increase in the percentage of the population potentially covered by physicians. The effectiveness improved in both hub municipalities. The findings confirmed the notion that more left-leaning coalitions tend to earmark more budget resources for social policies but encounter limits for overcoming structural inequalities and for converting their platform preferences into actual policies.

Health Systems; Dental Care; Medical Assistance; Political Factors

\section{Resumen}

Coaliciones de gobierno distintas encuentran límites para producir cambios en la orientación de politicas. El objetivo fue describir la orientación política de los partidos de coalición, el aporte financiero, la estructura y desempeño de la asistencia médica y odontológica en dos regiones de salud brasileñas, distintas socioeconómicamente y en la oferta de servicios. Se utilizaron indicadores a partir de datos oficiales relacionados con el período de 2007 a 2014 y características de la coalición partidaria, definidas por las preferencias electorales municipales y de intensidad en la competición electoral en cada estado de la respectiva región. Mayor aporte financiero per cápita y mayor porcentaje de población potencialmente cubierta por la atención básica y por los equipos de salud bucal de la Estrategia Salud de la Familia estaban relacionados con el municipio polo de la región de la coalición partidaria más a la izquierda, mientras que el municipio polo de la región de coalición partidaria más a la derecha mostró un aumento expresivo en el porcentaje de población potencialmente cubierta por médicos. En ambos municipios polo, la efectividad mejoró. Los resultados confirmaron la noción de que las coaliciones más a la izquierda aportan más recursos en políticas sociales, pero encuentran límites para superar desigualdades estructurales y convertir sus preferencias programáticas en políticas efectivas.

Sistemas de Salud; Atención Odontológica; Asistencia Médica; Factores Politicos
Recebido em 17/Mai/2021

Versão final reapresentada em 12/Set/2021 Aprovado em 21/Set/2021 